\title{
System-Based Participatory Research in Health Care: An Approach for Sustainable Transla- tional Research and Quality Improvement
}

\author{
Julie A Schmittdiel, $P b D^{1,2}$ \\ Kevin Grumbach, $M D^{2,3}$ \\ Joe V. Selby, MD, MPH ${ }^{1,2}$ \\ ${ }^{1}$ Division of Research, Kaiser Permanente \\ Medical Care Program, Northern Califor- \\ nia, Oakland, California \\ ${ }^{2}$ Community Engagement Program, Clinical \\ and Translational Science Institute, Uni- \\ versity of California, San Francisco, San \\ Francisco, California \\ ${ }^{3}$ Department of Family and Community \\ Medicine, University of California, San \\ Francisco, School of Medicine, San Fran- \\ cisco, California
}

Conflicts of interest: none reported

\section{CORRESPONDING AUTHOR}

Julie A Schmittdiel, PhD

Division of Research, Kaiser Permanente 2000 Broadway

Oakland, CA 94612

Julie.A.Schmittdiel@kp.org

\begin{abstract}
Translational research seeks to improve health care by promoting action and change in real-world health care settings. Although translational research advocates a break from the traditional researcher-initiated approach to science, strategies to successfully engage clinicians and leaders of health care delivery organizations in research are still under development. We propose that applying the principles of community-based participatory research in a way that considers delivery systems_-including their leaders, clinicians, and staff-as a focal community can enhance the ability of translational research to improve health care. Applying participatory research methods, such as engaging in collaborative partnerships, building on existing community strengths, investing in long-term relationships, and engaging in research as a cyclical, iterative process, can be a successful approach to sustainable quality improvement at the systems level.
\end{abstract}

Ann Fam Med 2010;8:256-259. doi:10.1370/afm.1117.

\section{INTRODUCTION}

$\mathrm{H}$ ealth care researchers and their funders, including the National Institutes of Health and the Agency for Healthcare Research and

Quality, increasingly point to translational research as a means to successfully incorporate research findings into health care practice. ${ }^{1,2}$ Translational research is defined as "the process of applying ideas, insights, and discoveries generated through basic scientific inquiry to the treatment or prevention of human disease." ${ }^{13}$ Although the term is often applied to the bench-to-bedside adaptation of basic science into new treatments, translational research also describes the translation of promising results from clinical studies into day-to-day medical practice. ${ }^{1}$ This "T2" translational research in health care emphasizes using research to promote action and change in real-world health care settings. ${ }^{1}$

Even though the promise of translational research is widely recognized, this nascent field's conceptual framework and methods are still developing. ${ }^{1}$ A traditional investigator-driven approach to research that fails to adequately engage patients, clinicians, and other key stakeholders within health care systems is a known barrier to translating research into practice ${ }_{r}^{4}$ often leading to interventions that are not sustainable in realworld environments.

Community-based participatory research (CBPR) is a conceptually rich alternative to traditional research paradigms that emphasizes partnership with community members in all phases of research activity. Our work in the Community Engagement Program of the University of California, San Francisco (UCSF) Clinical and Translational Science Institute (CTSI) has convinced us that the conceptual model and methods of CBPR can be fruitfully applied to translational research, including research partnerships with health delivery organizations. Participatory models for translational 
research should engage patients, individual clinicians and staff, and operational and administrative leaders of health systems in the research planning, implementation, and evaluation process.

\section{COMMUNITY-BASED PARTICIPATORY RESEARCH}

CBPR emphasizes equitable partnerships and promotes the sharing of power, knowledge, and resources between investigators and research participants in all stages of research and application. 5,6 This approach can be an important and successful strategy for public health improvement. ${ }^{7-9}$

CBPR is built on the principle that when users of research are brought in from the very beginning of the research-planning process, studies lead to stronger findings that are more practical and relevant to community needs. ${ }^{10}$ The community includes those directly affected by a given health issue and working toward a common goal. ${ }^{10,11}$ For translational research in health systems, we propose the community be defined to include health system leadership, as well as patients and clinic staff.

Practice-based research networks (PBRNs), in which community-based clinicians are actively engaged in research and quality improvement, are driven by the principles of participatory research ${ }^{12,13}$ and have led to many successful collaborations to improve

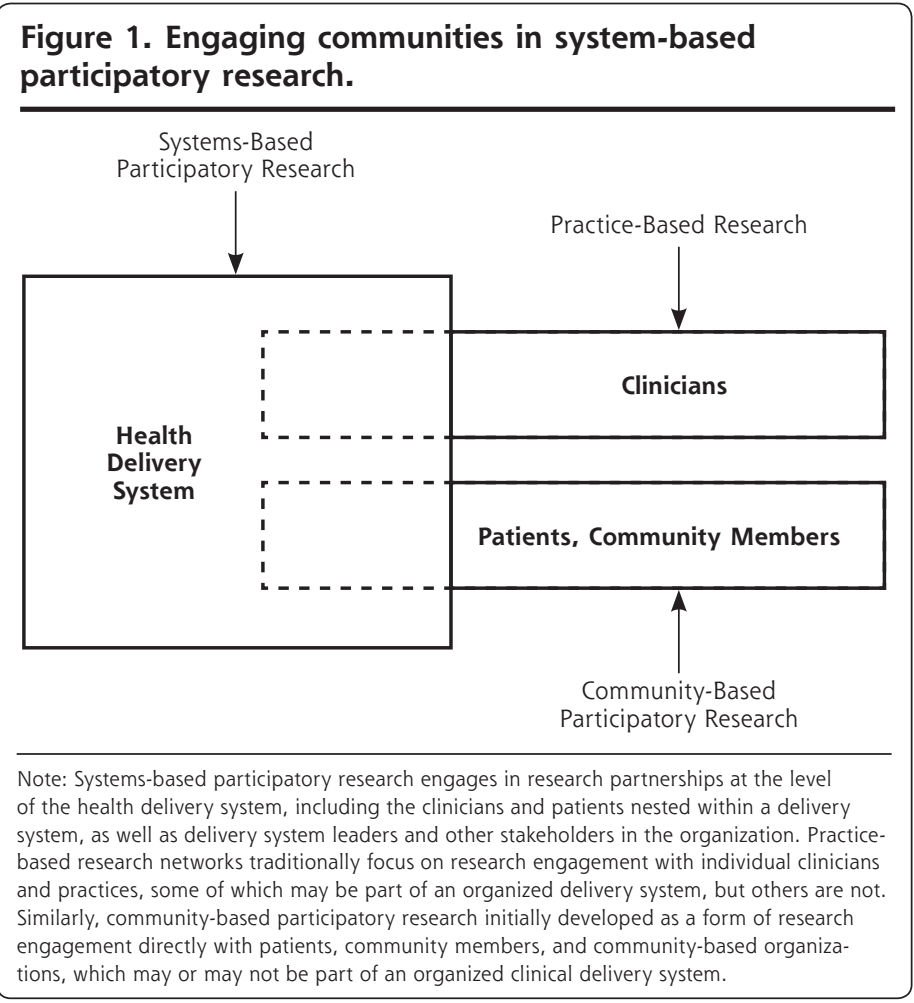

patient care. ${ }^{13-16}$ Whereas PBRNs provide an important paradigm for engaging clinicians in research, ${ }^{13}$ quality improvement often involves changes at the system level (such as widespread deployment of health information technology) that are typically influenced more by health care delivery system leadership than by individual clinicians.

We recognize broader health care delivery systems outside of PBRNs, such as community clinic consortia, local public health departments, and integrated delivery systems, as communities for research engagement analogous to patient groups and physician practices (Figure 1). These communities have leaders-chief administrators, medical directors - as well as frontline staff who will use and be affected by study findings. Reframing the principles of translational research in this context can provide useful insights into how to implement and sustain improvements in health care.

\section{Participatory Research Principles Applied to Health Systems}

CBPR draws on 4 key principles in engaging the community. ${ }^{17}$ These principles are outlined below, along with specific examples drawn from 2 health care systems: the San Francisco Community Health Network $(\mathrm{CHN})$, the public safety-net delivery system administered by the San Francisco Department of Public Health and affiliated with UCSF; and Kaiser Permanente, a comprehensive, integrated health care delivery system serving 3.4 million members in Northern California.

\section{Engage in Collaboration and Equitable} Partnerships in All Phases of Research All phases of research include choosing the research questions, designing and conducting the study, and translating important findings into action. This approach represents a radical departure from current practice for most health care researchers. Researchers often reach out to health care delivery systems only after the research question and study design have been chosen, and sometimes not until a proposal has been funded. Involving health systems in research design, however, is likely to improve the chances that the study will be successful and lead to results that are useful to the community.

UCSF investigators and the clinical leadership of the Chinatown Community Health Center, a CHN primary care clinic, partnered to implement and evaluate a program offering colorectal cancer screening kits to patients receiving annual influenza (flu) shots. The 
effectiveness of distributing kits to test stool for occult blood during nurse-provided flu shot clinics for increasing colorectal screening rates has been demonstrated in a randomized clinical trial. ${ }^{18}$ Translating this model in a way that was suitable to the Chinatown clinic required close collaboration between the university investigator and clinic medical and nursing leaders. For example, nurses in the Chinatown clinic identified the need to develop visual aids that could be used to quickly show how to use the colorectal screening kits in a method appropriate to the clinic's busy workflow and patients' culture and language. By working together from the project's inception, the investigator and clinic leaders built an intervention that is well-adapted to the system's patients and operating methods and that will be sustainable once the research phase is complete.

\section{Build on the Resources and Goals Already Present in the Community}

Health care delivery systems and clinical practices have goals they are striving to achieve and perceived barriers to reaching those goals. These goals can include quality improvement, such as achieving Healthcare Effectiveness Data and Information Set (HEDIS) performance targets, implementing an electronic health record, or improving care coordination. Such goals may provide the impetus for harnessing organizational energy and resources in the research process rather than competing with the organization's priorities.

A major goal of Kaiser Permanente Northern California is to improve preventive care for patients at high risk for cardiovascular disease through its PHASE (Preventing Heart Attacks and Strokes Everyday) program, using nonphysician panel managers to improve risk factor management and control. Two of the authors (J.A.S., J.V.S.) worked closely with these panel managers to develop a modification of the program to more accurately identify patients in need of treatment intensification. Through this collaboration, collection of study data was incorporated into the PHASE program in a way that was compatible with existing information systems and patient outreach strategies. The close partnership between PHASE leaders and investigators enabled the intervention to be evaluated using a cluster randomized design in a study that obtained federal funding.

\section{Create and Invest in Long-Term and Robust Partnerships}

To have a lasting impact on clinical practice, researchers must engage in long-term relationships with health systems: true participatory research must be sustained beyond the life-span of a single study. The Clinical and Translational Science Awards, funded by the National
Institutes of Health, are built on the premise of strengthening these interdisciplinary relationships, and the CTSI at the UCSF provides ongoing support to investigators embedded within the $\mathrm{CHN}$ and Kaiser Permanente delivery systems.

The Community Engagement Program's ongoing partnership with the CHN affords opportunities to spread interventions beyond their original evaluation site. CTSI investigators developed a novel intervention using automated computer-assisted telephone calls in different languages to provide culturally appropriate diabetes care management to patients in the $\mathrm{CHN} .{ }^{19}$ The strong relationship between the investigators and the county Medicaid managed care plan (a major payer for $\mathrm{CHN}$ clinics), as well as the intervention's proven appropriateness for safety net clinics, has led the Medicaid plan to provide resources to implement this intervention throughout the $\mathrm{CHN}$.

Engage in Research as a Cyclical, Iterative Process Ideally, successful research projects lead to quality improvement in the community through the process of translation and dissemination. When true partnerships exist between researchers and health systems, however, ideas flow in both directions. Researchers who study the implementation of quality improvement and are engaged in the kinds of long-term partnerships described above should find important areas for new scientific inquiry.

This type of cyclical process is occurring with the PHASE project. Kaiser Permanente researchers continue working with operational staff to refine the intervention described above, and supported by grants from Kaiser Permanente Community Benefit, PHASE is now being implemented within the $\mathrm{CHN}$ and other safety net systems in California. UCSF investigators are studying the process of adapting PHASE to populations and delivery systems very different from those of the original Kaiser Permanente setting. Similarly, some Kaiser facilities are now adopting and adapting the flu shot-colorectal screening intervention developed at the CHN clinics, with new research grants supporting evaluation of this process.

\section{CHALLENGES}

Applying participatory research principles to translational research is challenging. Although investigators, delivery system leaders, and clinicians all strive to improve health care quality, they often operate under differing timelines, contexts, and reward systems. ${ }^{4}$ For example, systems are interested in rapid quality improvement, but traditional research funding may arrive so late that an organization's goals or strategies may have changed. The Agency for Health care Research and 
Quality's use of rapid cycle funding mechanisms, as well as impending changes to the review process at the National Institutes of Health, may help address this issue. ${ }^{20}$ As with CBPR, it will take time and effort for researchers, funders, and the community of health care system leaders to bridge these differences.

Incorporating participatory research principles into T2 translational research is essential if this research is to fully succeed in improving clinical care. Engaging health care systems as a form of community partner increases the likelihood that research questions will be relevant, interventions sustainable, and research findings translated into systematic action.

To read or post commentaries in response to this article, see it online at http://www.annfammed.org/cgi/content/full/8/3/256.

Key words: Translational research; participatory research; quality improvement

Submitted July 5, 2009; submitted, revised, October 10, 2009; accepted November 9, 2009.

Funding support: This publication was supported by the National Institutes of Health/National Center for Research Resources and University of California, San Francisco, Clinical and Translational Science Institute grant No. UL1 RR024131. Dr Schmittdiel is supported by the Office of Research in Women's Health Building Interdisciplinary Careers in Women's Health K12 Career Development Award (K12HD052163). Dr Selby is supported by the Agency for Healthcare Research and Quality, grant No. 5R18HS017031-02.

Disclaimer: Its contents are solely the responsibility of the authors and do not necessarily represent the official views of the National Institutes of Health.

\section{References}

1. Woolf $\mathrm{SH}$. The meaning of translational research and why it matters. JAMA. 2008;299(2):211-213.

2. Clancy CM, Slutsky JR, Patton LT. Evidence-based health care 2004: AHRQ moves research to translation and implementation. Health Serv Res. 2004;39(5):xv-xxiii.

3. Translational Research: Exploratory/Developmental Projects. National Institute of Neurological Disorders and Strokes. http://www. ninds.nih.gov/funding/nindsnotes/112008/. Accessed Apr 27, 2010.

4. Green LW. Making research relevant: if it is an evidence-based practice, where's the practice-based evidence? Fam Pract. 2008; 25(Suppl 1):i20-i24.
5. Hall BL. From margins to center? The development and purpose of participatory research. Am Sociol. 1992;23(4):15-28.

6. Minkler M, Wallerstein N, eds. Community Based Participatory Research for Health. San Francisco, CA: Jossey-Bass \& Co; 2003.

7. Jones $L$, Wells $K$. Strategies for academic and clinician engagement in community-participatory partnered research. JAMA. 2007;297(4): 407-410.

8. Green LW, Mercer SL. Can public health researchers and agencies reconcile the push from funding bodies and the pull from communities? Am J Public Health. 2001;91(12):1926-1929.

9. Leung MW, Yen IH, Minkler M. Community based participatory research: a promising approach for increasing epidemiology's relevance in the 21st century. Int J Epidemiol. 2004;33(3):499-506.

10. Cargo M, Mercer SL. The value and challenges of participatory research: strengthening its practice. Annu Rev Public Health. 2008; 29:325-350.

11. Mold JW, Pasternak A, McCaulay A, et al.; Practice-Based Research Subcommittee of North American Primary Care Research Group Committee on Advancing Science of Family Medicine. Definitions of common terms relevant to primary care research. Ann Fam Med. 2008;6(6):570-571.

12. Mold JW, Peterson KA. Primary care practice-based research networks: working at the interface between research and quality improvement. Ann Fam Med. 2005;3(Suppl 1):S12-S20.

13. Westfall JM, Fagnan LJ, Handley M, et al. Practice-based research is community engagement. J Am Board Fam Med. 2009;22(4):423-427.

14. Mold JW, Gregory ME. Best practices research. Fam Med. 2003; 35(2):131-134.

15. Parchman ML, Munoz A. Risk factors for methicillin-resistant Staphylococcal aureus skin and soft tissue infections presenting in primary care: a South Texas Ambulatory Research Network (STARNet) study. J Am Board Fam Med. 2009;22(4):375-379.

16. Froshaug DB, Dickinson LM, Fernald DH, Green LA. Personal health behaviors are associated with physical and mental unhealthy days: a Prescription for Health (P4H) practice-based research networks study. J Am Board Fam Med. 2009;22(4):368-374.

17. Israel BA, Schulz AJ, Parker EA, Becker AB; Community-Campus Partnerships for Health. Community-based participatory research: policy recommendations for promoting a partnership approach in health research. Educ Health (Abingdon). 2001;14(2):182-197.

18. Potter MB, Phengrasamy L, Hudes ES, McPhee SJ, Walsh JM. Offering annual fecal occult blood tests at annual flu shot clinics increases colorectal cancer screening rates. Ann Fam Med. 2009; $7(1): 17-23$.

19. Schillinger D, Handley M, Wang F, Hammer H. Effects of selfmanagement support on structure, process, and outcomes among vulnerable patients with diabetes: a three-arm practical clinical trial. Diabetes Care. 2009;32(4):559-566.

20. Johnston SC, Hauser SL. Peer review at National Institutes of Health: small steps forward. Ann Neurol. 2008;64(5):A15-A17. 